\section{Role of standardized eccentric compression to reduce the varicose vein volume of $70 \%$}

\author{
Vincent Crébassa \\ Clinique du Millenaire, Montpellier, \\ France
}

\begin{abstract}
The main pitfall of our treatments is the presence of blood in the treated varicose vein.

Thus, reducing it diameter during and after treatments is a fundamental therapeutic objective.

Digressive compression don't alter the diameter of the saphenous veins explaining some doubts about it efficiency. This is why we make eccentric compressions, often artisanal.

The main of this study is the reduction of the diameter of the varicose vein under standardized eccentric compression, according to the territory of these varicose vein, their supra-facial situations or in the saphenous compartment situations, according to their depth, their nature: primitive or recurrence, in lying and standing positions.
\end{abstract}

We measured 130 legs from 85 patients. A rectangular window was cut in the device for measuring the diameters and depths of varicose veins. The pressure sensor checked the interface pressure delivered by the compression device.

The average patient age was 60 years old. Measurements confirmed the existence of a minimum pressure of $50 \mathrm{~mm} \mathrm{Hg.} 77 \%$ were GSV, $23 \%$ were SSM, 95\% primary varicose vein and $5 \%$ recurrences. $74 \%$ of varicose veins had a sub-fascial localization, $26 \%$ supra-fascial.

In lying position the superficial varicose veins reduce their diameter by $43 \%$, the saphenous veins by $36 \%$. In standing position respectively $36 \%$ and $33 \%$.

This external tumescence allows a reduction in diameter of at least $43 \%$, thus, $70 \%$ reduction in their volume. This reduction may be even better with an additional $75 \%$ stretch. It can be placed on the calf or on the thigh during the treatment but especially after the treatments to reduce side effects (local pains, pigmentations, thrombectomies), complications and promotes harmonious fibrosis. It allows the reduction of the volumes and concentrations injected in the case of foam sclerosis.
Correspondence: Vincent Crébassa, Clinique du Millenaire, 220 Boulevard Pénélope, 34000 Montpellier, France.

E-mail: vcrebassa@club-internet.fr

Conference presentation: International Compression Club (ICC) Meeting, Paris, 2017

This work is licensed under a Creative Commons Attribution 4.0 License (by-nc 4.0).

C Copyright V. Crébassa, 2018

Licensee PAGEPress, Italy

Veins and Lymphatics 2018; 7:7630

doi:10.4081/vl.2018.7630

\section{References}

1. Jünger M, Konschake W, Haase H, Riebe H. Compression stockings with interface pressure fall and rise from the ankle to the mid calf. Veins and Lymphatics 2017;6:6632.

2. Chi Y-W. A new compression pressure measuring device. Veins and Lymphatics 2017;6:6636.

3. Chassagne F, Badel P, Convert R, et al Experimental and numerical approach for the investigation of interface pressure applied by compression bandages. Veins and Lymphatics 2017;6:6626. 